\title{
Comparison of different biomass pretreatment techniques and their impact on chemistry and structure
}

\author{
Seema Sing $h^{1,2} *$, Gang Cheng ${ }^{1,2 \dagger}$, Noppadon Sathitsuksanoh ${ }^{1,2}$, Dong Wu ${ }^{1,2}$, Patanjali Varanasi ${ }^{1,2}$, \\ Anthe George ${ }^{1,2}$, Venkatesh Balan ${ }^{3}$, Xiadi Gao ${ }^{4,5,6}$, Rajeev Kumar ${ }^{4,6}$, Bruce E. Dale ${ }^{3}$, Charles E. Wyman ${ }^{4,5,6}$ and \\ Blake A. Simmons ${ }^{1,2}$ \\ 1 Deconstruction Division, Joint BioEnergy Institute (JBEI), Emeryville, CA, USA \\ 2 Sandia National Laboratories, Biological and Materials Sciences Center, Livermore, CA, USA \\ ${ }^{3}$ Department of Chemical Engineering and Materials Science, DOE Great Lakes BioEnergy Research Center (GLBRC), Michigan State University, Lansing, MI, USA \\ ${ }^{4}$ Oak Ridge National Laboratory, BioEnergy Science Center (BESC), Oak Ridge, TN, USA \\ ${ }^{5}$ Department of Chemical and Environmental Engineering, Bourns College of Engineering, Riverside, CA, USA \\ ${ }^{6}$ Center for Environmental Research and Technology (CE-CERT), Bourns College of Engineering, University of California Riverside, Riverside, CA, USA
}

Edited by:

Wei-Hsin Chen, National Cheng Kung University, Taiwan

Reviewed by:

Charilaos Xiros, Chalmers University

of Technology, Sweden

Fei Shen, Sichuan Agricultural

University, China

Yunqiao Pu, Georgia Institute of

Technology, USA

${ }^{*}$ Correspondence:

Seema Singh, Joint BioEnergy

Institute (JBEI), 5885 Hollis Street,

Emeryville, CA 94608, USA

e-mail: seesing@sandia.gov

${ }^{\dagger}$ Present address:

Gang Cheng, Beijing Key Laboratory of Bioprocess, Beijing University of

Chemical Technology, Beijing, China

AFEX ${ }^{T M}$ is a trademark of MBI

International, Lansing, Michigan
Pretreatment of lignocellulosic biomass is a prerequisite to overcome recalcitrance and allow enzyme accessibility to cellulose and maximize product recovery for improved economics of second-generation lignocellulosic bio-refineries. Recently, the three US-DOE funded Bioenergy Research Centers [Joint Bioenergy Institute (JBEI), Great Lakes Bioenergy Research Center (GLBRC), and BioEnergy Science Center (BESC)] compared ionic liquid (IL), dilute sulfuric acid (DA), and ammonia fiber expansion ( $A F E X^{\top \mathrm{M}}$ ) pretreatments and published comparative data on mass balance, total sugar yields, substrate accessibility, and microbial fermentation [Biotechnology for Biofuels 7: 71; 72 (2014)]. In this study, corn stover solids from IL, DA, and AFEX pretreatments were compared to gain comprehensive, in-depth understanding of induced morphological and chemical changes incorporated to corn stover, and how they overcome the biomass recalcitrance. These studies reveal that biomass recalcitrance is overcome by combination of structural and chemical changes to carbohydrates and lignin after pretreatment. Thermal analysis indicates that AFEX and IL pretreated corn stover showed a lower thermal stability while DA pretreated corn stover showed the opposite. The surface roughness variations measured by small-angle neutron scattering were correlated to the removal and redistribution of biomass components and was consistent with compositional analysis, atomic force microscopy (AFM) and confocal fluorescence imaging results. With AFM and confocal fluorescent microscopy, lignin was found to be re-deposited on cellulose surface with average cellulose fiber width significantly decreased for DA pretreated corn stover (one-third of IL and AFEX). HSOC NMR spectra revealed a $\sim 17.9 \%$ reduction of $\beta$-aryl ether units after AFEX, $\sim 59.8 \%$ reduction after DA, and $>98 \%$ reduction after IL. Both NMR and size exclusion chromatography showed similar patterns of lignin de-polymerization with highest degree of de-polymerization observed for IL followed with DA and AFEX.

Keywords: corn stover, pretreatment, biomass characterization, recalcitrance

\section{INTRODUCTION}

Lignocellulosic biomass is considered as sustainable and renewable feedstock to produce biofuels that is alternative to petroleum derived fuels. In order to realize this potential, lignocellulosic biomass must be pretreated to overcome recalcitrance (Yang and Wyman, 2008; da Costa Sousa et al., 2009). There are numerous physico-chemical factors that contribute to lignocellulosic recalcitrance. Substantial work is being done to commercially develop scalable and economical pretreatment technologies that dramatically enhance biological conversion of resulting pretreated solids and total sugar yields for downstream fermentation processes (Balan et al., 2013). Pretreatment of biomass is an essential processing step for producing biofuels with high yields via biological routes (Haghighi Mood et al., 2013).The interactions between pretreatment and plant cell walls determine their compositional and structural changes, which ultimately affect the extent of enzymatic hydrolysis (Ong et al., 2014). To identify various recalcitrant structures present in plant cell walls, substrate-related properties such as cellulose crystallinity and lattice structure, cellulose accessibility, and extent of lignifications have been correlated with sugar production efficiency (Chundawat et al., 2011; Yang et al., 2011; Foston and Ragauskas, 2012; Zhao et al., 2012; Pu et al., 2013; Singh et al., 2014). Those factors are often coupled together and their relative contributions to the biomass recalcitrance can vary greatly, depending on the types of biomass and enzymes as well as the pretreatment conditions, etc. (Yang et al., 2011; Foston and Ragauskas, 2012; Zhao et al., 2012). 
The three US Department of Energy (DOE) funded bioenergy research centers (BRCs), the Joint BioEnergy Institute (JBEI), BioEnergy Science Center (BESC), and Great Lakes Bioenergy Research Center (GLBRC) are developing and optimizing ionic liquid (IL), dilute sulfuric acid (DA), and ammonia fiber expansion (AFEX) pretreatment technologies, respectively. DA pretreatment is one of the pretreatment methods used for second-generation biofuel production (Saha et al., 2005; Sun and Cheng, 2005; Foston and Ragauskas, 2010; Cao et al., 2012; Gao et al., 2013), and has been known to effectively solubilize hemicelluloses from biomass. AFEX pretreatment has been shown to be capable of breaking off ester and lignin-carbohydrate bonds and increasing cellulose enzyme accessibility by producing nanoporous tunnellike networks (Balan et al., 2009; Lau and Dale, 2009; Chundawat et al., 2011; Harun et al., 2013; Bals et al., 2014). IL pretreatment is a relatively new technology and it can decrease lignin content and convert microcrystalline cellulose to its amorphous form or decrease its crystallinity (Singh et al., 2009; Mora-Pale et al., 2011; Tadesse and Luque, 2011; Brandt et al., 2013). Certain ILs, such as 1-ethyl-3-methylimidazolium acetate (abbreviated as $\left[\mathrm{C}_{2} \mathrm{C}_{1} \mathrm{Im}\right][\mathrm{OAc}]$ ), have been found to completely dissolve the biomass at specific operating conditions, and hence provide a unique platform to fractionate the three major components of biomasscellulose, hemicellulose, and lignin (Verdia et al., 2014). All three pretreatments are capable of decreasing biomass recalcitrance via morphological and physico-chemical changes.

Due to the complex nature of the interactions between biomass and pretreatment, comparative evaluations of different pretreatment technologies on single substrate would offer important insights into the mechanism of the pretreatment processes since it eliminates substrate variability. Literature reports on this comparative study are relatively scant, partly because it requires collaborations between different groups and institutions. There have been a number of studies focused on comparing DA and AFEX pretreatment techniques on corn stover, poplar, and switchgrass (Kumar et al., 2009; Lau et al., 2009; Chundawat et al., 2010; Garlock et al., 2011; Kim et al., 2011; Pallapolu et al., 2011; Tao et al., 2011; Wyman et al., 2011). In contrast, comparative studies between IL and DA (Li et al., 2010, 2013), IL and AFEX (Li et al., 2011) pretreatment are few in number, due in part to the fact that IL pretreatment is a relatively new approach. To gain a better understanding of IL, DA, and AFEX pretreatments and to provide a side-by-side comparison of these technologies, the BRCs used the same cultivar of corn stover processed and distributed between institutions for pretreatment. Samples of the IL, DA, and AFEX pretreated corn stover were then exchanged to investigate and compare enzyme accessibility and sugar yields (BESC), cocktail optimization, mass balance, and fermentation (GLBRC), and thermo, physico-chemical changes to corn stover upon pretreatment (JBEI).

This work correlates the impact of all three different pretreatments on corn stover using a wide range of analytical approaches to provide new insights into the mechanisms and impacts of each. Thermo-gravimetric analysis (TGA) was used to study thermal behavior of biomass (Muhammad et al., 2012; Poletto et al., 2012; Singh et al., 2013; Zhang et al., 2014). The changes in percent crystallinity and the crystalline structure of the cellulose in pretreated corn stover were analyzed using $\mathrm{X}$-ray diffraction (XRD). Small-angle neutron scattering (SANS), confocal fluorescence microscopy and atomic force microscopy (AFM) were used to track the changes in surface morphologies of biomass as a result of the different pretreatment methods (Singh et al., 2009; Cheng et al., 2011; Li et al., 2011). NMR (Kim et al., 2008; Yelle et al., 2008, 2013; Cetinkol et al., 2009, 2012; Kim and Ralph, 2010; Samuel et al., 2011a,b) and size exclusion chromatography (SEC) (Gidh et al., 2006; George et al., 2011; Sathitsuksanoh et al., 2014) were used to chemically characterize the different linkages present in the corn stover and lignin breakdown and size distribution. These results provide a new comparative insight into the effects of biomass pretreatment and help explain recalcitrance factors that are important to overcome for high sugar yields.

\section{MATERIALS AND METHODS}

The corn stover used in this study was obtained from Michigan State University Farms (East Lansing, MI, USA). The corn hybrid used was NK 49-E3 (Syngenta, Basel, Switzerland), which is a typical CS hybrid used in the Great Lakes Region, and was harvested in September of 2008. The harvested biomass was shreadded into fine pieces followed by air drying in room temperature until the moisture content of biomass was $<10 \%(\mathrm{dwb})$. Then it was further size reduced using a Wiley mill with a $2-\mathrm{mm}$ diameter sieve and then stored in refrigerator until further use. By following the National Renewable Energy Laboratory (NREL, Denver, CO, USA) protocols, the composition of untreated corn stover was $33.4 \%$ glucan, $24.9 \%$ xylan, $3.7 \%$ arabinan, $2.1 \%$ acetyl, $17.2 \%$ insoluble lignin, $3.6 \%$ ash, and $10.4 \%$ extractives. All compositions are on dry biomass basis.

\section{PRETREATMENT OF CORN STOVER Ionic liquid pretreatment}

Ionic liquid pretreatment of corn stover was conducted using 1-ethyl-3-methylimidazolium acetate, abbreviated as $\left[\mathrm{C}_{2} \mathrm{C}_{1} \mathrm{Im}\right][\mathrm{OAc}]$, purchased from $\mathrm{BASF}(\geq 90 \%$, cat \#51053) and used as received. The pretreatment was conducted at $140^{\circ} \mathrm{C}$ for $3 \mathrm{~h}$ using $15 \%$ (wt/wt) loading of biomass. After the pretreatment process, biomass was separated from IL and purified using a series of ethanol and water washes. The composition of IL treated corn stover was $46.9 \%$ glucan, $29.8 \%$ xylan, $0.3 \%$ arabinan, $1.5 \%$ acetyl, $2.7 \%$ insoluble lignin, $1.3 \%$ ash, and $13.1 \%$ extractives.

\section{Dilute acid pretreatment}

Dilute acid pretreatment was performed at $160^{\circ} \mathrm{C}$ for $20 \mathrm{~min}$ with $10 \% \mathrm{w} / \mathrm{w}$ solid loading and $0.5 \% \mathrm{w} / \mathrm{w}$ sulfuric acid using a $1 \mathrm{~L}$ Parr reactor with two stacked pitched blade impellers (Model 4525, Parr Instruments Company, Moline, IL, USA). The heating system was a 4-kW model SBL-2D fluidized sand bath (Techne, Princeton, NJ, USA). The composition of DA treated corn stover was $59.1 \%$ glucan, $6.5 \%$ xylan, $3.6 \%$ arabinan, $0 \%$ acetyl, $22.2 \%$ acid insoluble lignin, $2.5 \%$ ash, and $15.4 \%$ extractives.

\section{Ammonia fiber expansion pretreatment}

Ammonia fiber expansion pretreatment procedure was similar to the one described previously by Balan et al. (2009) AFEX pretreatment conditions used in this study include: Ammonia to dry 
biomass loading 1:1, biomass moisture 60\% (dry biomass weight basis), temperature $140^{\circ} \mathrm{C}$, and a residence time $15 \mathrm{~min}$. Pretreatment was done in a high pressure stainless steel reactor system (Parr Instrument Co, IL, USA). Pretreated biomass was dried in the hood overnight to remove residual ammonia and then packed and stored in zip lock bags in a refrigerator with $<10 \%$ moisture until further use. The composition of AFEX treated corn stover was $33.5 \%$ glucan, $24.8 \%$ xylan, $3.3 \%$ arabinan, $0.6 \%$ acetyl, $17.2 \%$ insoluble lignin, $4.3 \%$ ash, and $24.8 \%$ extractives.

\section{X-RAY DIFFRACTION MEASUREMENT}

$\mathrm{X}$-ray diffraction measurements were performed on a PANalytical Empyrean system equipped with a PIXcel ${ }^{3 \mathrm{D}}$ detector. The BraggBrentano geometry comprises a $\mathrm{Cu}$ X-ray tube (operated at $45 \mathrm{kV}$ and $40 \mathrm{~mA} ; \lambda=1.5418 \AA$ ), incident beam optics with a $1 / 8^{\circ}$ fixed divergence and a $1 / 4^{\circ}$ anti scatter slit, as well as a 0.04 radian soller slit and receiving optics, which include another 0.04 radian soller slit, a Ni $K_{\beta}$ filter, and the PIXcel ${ }^{3 \mathrm{D}}$ detector in scanning mode. A reflection-transmission spinner was used as a sample holder and the spinning rate was set at $8 \mathrm{rpm}$ throughout the experiment. The patterns were collected in the $2 \theta$ range of $5-65^{\circ}$, the step size was $0.026^{\circ}$, and the exposure time was $300 \mathrm{~s}$. The crystallinity index $(\mathrm{CrI})$ was determined by a curve fitting procedure of the measured diffraction patterns using with the software package HighScore Plus ${ }^{\circledR}$.

\section{SMALL-ANGLE NEUTRON SCATTERING}

Small-angle neutron scattering experiments were conducted at Oak Ridge National Laboratory (ORNL) on the CG2 (GP-SANS) instrument (http://neutrons.ornl.gov/gpsans/) with a neutron wavelength of $\lambda=4.8 \AA(\Delta \lambda / \lambda \sim 0.14)$. Powder samples were sandwiched into $1 \mathrm{~mm}$ home-made quartz cells. Two sampledetector distances were used $(1.5$ and $14.5 \mathrm{~m}$ with a $40 \mathrm{~cm}$ detector offset), which resulted in an overall $q$ range of $0.004 \AA^{-1}<q=4 \pi$ $\sin \theta / \lambda<0.5 \AA^{-1}$. The data were corrected for instrumental background and detector efficiency. Due to uncertainty in the packing density of the powder in the cells, the absolute scattering intensities are reported without normalization to sample mass or volume.

\section{ATOMIC FORCE MICROSCOPY}

Asylum Research MFP-3D-Bio atomic force microscopy system was used to image pretreated corn stover. All the biomass samples were fixed on small metal plate. Since the samples were not of regular shape and do not have a flat surface for AFM imaging, the pretreated corn stover samples were first spread gently and homogenously on the metal plate after painting a thin layer of epoxy used to fix the samples. Then, a freshly peeled mica thin layer was used to press against the biomass samples to generate a less rough and flat surface. After the epoxy was dried using nitrogen gas to spray off the top covered mica. Due to the steep surface slope we selected a high aspect ratio cantilever (MSS_FMP-13 from NanoTools) as our AFM probe. For each type of biomass samples, the scan size ranged from couple of micron to couple $100 \mathrm{~nm}$ with highest resolution $<1 \mathrm{~nm}$. All the images were processed using the Igor software from Asylum Research AFM systems.

\section{CONFOCAL FLUORESCENT MICROSCOPE}

The confocal fluorescent microscope images were taken using Zeiss LSM 710 with two laser sources (405 and $488 \mathrm{~nm}$ ). The samples were directly imaged without any modification on the thin glass cover slide using 40X and 10X objectives.

\section{THERMO-GRAVIMETRIC ANALYSIS}

Thermo-gravimetric analysis consists of measuring the decrease of mass of a sample with increasing temperature. TGA was conducted using a TGA/DSC system $\left(\mathrm{STAR}^{\mathrm{e}}\right.$ system, Mettler-Toledo, Inc., Colombus, OH, USA) equipped with a high throughput auto sampler. A $5 \mathrm{mg}$ of sample was weighed into $40 \mu \mathrm{l}$ aluminum crucible and analyzed in the presence of Argon $(10 \mathrm{ml} / \mathrm{min})$ under isothermal conditions. The temperature of the sample and the reference cell was ramped at a rate of $10^{\circ} \mathrm{C} / \mathrm{min}$ from 35 to $500^{\circ} \mathrm{C}$. The change in the mass of the sample was recorded by the microbalance in the TGA instrument. The first differential (DTG) curves of the TGA curves are easier to read and infer from when compared to the TGA curves. The plot shown in this work represents dTG curves of the original TGA curves obtained from the instrument. The untreated corn stover samples were compared to pretreated samples for changes in the decomposition temperature and weight loss percent.

\section{D ${ }^{13} \mathrm{C}-{ }^{1} \mathrm{H}$ HSOC NMR ANALYSIS}

Corn stover cell walls from different pretreatments were ballmilled, solubilized in DMSO- $\mathrm{d}_{6}$, and then analyzed by 2D HSQC NMR. 2D ${ }^{13} \mathrm{C}-{ }^{1} \mathrm{H}$ HSQC NMR of plant cell wall samples were performed as previously described (Kim and Ralph, 2010). In short, ball-milled samples $(\sim 50 \mathrm{mg})$ were then placed in NMR tubes with $600 \mu \mathrm{l}$ DMSO- $\mathrm{d}_{6}$. The samples were sealed and sonicated until homogenous in a Branson 2510 tabletop cleaner (Branson Ultrasonic Corporation, Danburt, CT, USA). The temperature of the bath was closely monitored and maintained below $55^{\circ} \mathrm{C}$. HSQC spectra were acquired at $398 \mathrm{~K}$ using a Bruker Avance$600 \mathrm{MHz}$ instrument equipped with a $5 \mathrm{~mm}$ inverse-gradient ${ }^{1} \mathrm{H} /{ }^{13} \mathrm{C}$ cryoprobe using a q_hsqcetgp pulse program (ns $=64$, $\mathrm{ds}=16$, number of increments $=256, d_{1}=1.5 \mathrm{~s}$ ) (Heikkinen et al., 2003). Chemical shifts were referenced to the central DMSO peak $\left(\delta_{C} / \delta_{H} 39.5 / 2.5 \mathrm{ppm}\right)$. Assignment of the HSQC spectra was described elsewhere (Kim and Ralph, 2010). A semi-quantitative analysis of the volume integrals of the HSQC correlation peaks was performed using Bruker's Topspin 3.1 (Windows) processing software.

\section{ISOLATION OF ENZYMATIC MILD ACIDOLYSIS LIGNIN}

Ball-milling of untreated corn stover was performed using a Retsch PM 100 planetary ball mill spinning at $600 \mathrm{rpm}$ with zirconium dioxide $\left(\mathrm{ZrO}_{2}\right)$ container and balls. The ball-milling conditions were described elsewhere (Kim and Ralph, 2010). Briefly, the ballmilled biomass samples were treated with cellulase (Cellic ${ }^{\circledR}$ CTec2 of Novozymes) and hemicellulase (Cellic ${ }^{\circledR}$ HTec2 of Novozymes) in the amount of $50 \mathrm{mg}$ protein/g biomass. The enzymatic hydrolysis was carried out at $50^{\circ} \mathrm{C}$ for $48 \mathrm{~h}$ at $2 \%$ consistency in the presence of $2 \%$ Tween 20 in $50 \mathrm{mM}$ citrate buffer ( $\mathrm{pH} \sim 4.8$ ). The insoluble materials were washed with deionized water and a fresh batch of enzymes, in the same quantity, was added for another 
$48 \mathrm{~h}$. The insoluble materials remaining after enzymatic hydrolysis were washed with deionized water to remove soluble sugars. Residual proteins on the surface of solid pellets were then washed twice with $6 \mathrm{M}$ guanidine hydrochloride $(\mathrm{GndHCl})$ and freeze dried. The crude lignin obtained was further subjected to mild acid hydrolysis using an azeotrope of dioxane-water [96:4 (v/v)] containing 0.01 N $\mathrm{HCl}$ under nitrogen atmosphere. The resulting suspension was centrifuged, and the supernatant was collected. The supernatant was neutralized with $2 \mathrm{M}$ sodium bicarbonate and then added drop-wise into $1 \mathrm{~L}$ acidified water $(\mathrm{pH} 2.0)$. The precipitated lignin was allowed to equilibrate overnight, recovered by centrifugation, washed with deionized water twice, and freeze dried.

\section{SIZE EXCLUSION CHROMATOGRAPHY}

To understand changes of lignin molecular weight distribution during pretreatment, SEC was performed on extracted lignin from pretreated corn stover. An Agilent 1200 series binary LC system (G1312B) equipped with diode-array (G1315D) and fluorescence (G1321A) detectors was used. Separation was achieved with a Mixed-D column ( $5 \mu \mathrm{m}$ particle size, $300 \times 7.5 \mathrm{~mm}$ i.d., linear molecular weight range of 200-400,000 u, Polymer Laboratories) at $80^{\circ} \mathrm{C}$ using a mobile phase of NMP at a flow rate of $0.5 \mathrm{ml}$ per min. Absorbance of materials eluting from the column was detected at $300 \mathrm{~nm}$ (UVA) as well as excitation at $250 \mathrm{~nm}$ and emission at $450 \mathrm{~nm}$ were used for UVF. Intensities were area-normalized and molecular mass estimates were determined after calibration of the system with polystyrene standards (George et al., 2011). The enzymatic mild acidolysis lignin (EMAL) process (Guerra et al., 2006) was used to extract lignin from corn stover and this was used as both the process control and the initial material for the three pretreatments.

\section{RESULTS AND DISCUSSION \\ EFFECT OF PRETREATMENT ON CELLULOSE CRYSTALLINITY}

The XRD of untreated and treated corn stover samples are presented in Figure 1. There are three broad peaks at $16.3^{\circ}, 21.9^{\circ}$, and $35.0^{\circ}$ for untreated corn stover, which are consistent with cellulose I lattice. The broad peak at $16.3^{\circ}$ is a composite from several peaks (Cheng et al., 2011). Upon pretreatment in [ $\left.\mathrm{C}_{2} \mathrm{C}_{1} \mathrm{Im}\right][\mathrm{OAc}]$, the cellulose becomes amorphous while cellulose I lattice is preserved in the DA and AFEX samples. Although the main peak position remains roughly the same for the DA and AFEX samples, there are noticeable shifts of the secondary peak from $16.3^{\circ}$ to $15.8^{\circ}$ upon DA pretreatment. The fraction of crystalline cellulose in the corn stover sample, defined as the biomass CrI, was estimated by comparing area under the XRD pattern to that of an amorphous lignin sample. There is an apparent increase of biomass CrI for DA pretreated corn stover while for the AFEX pretreated one, it stays roughly constant (Figure 1). The apparent increase in CrI is caused by the removal of amorphous hemicelluloses by the DA pretreatment. However, the true impact of pretreatment on the cellulose crystalline structure is the change in cellulose CrI. Taking into consideration of the weight fraction of glucan in the samples (see Materials and Methods), the cellulose CrI in untreated, AFEX and DA pretreated samples are 1.0,0.98, and 0.82, respectively. Depending on the pretreatment conditions, AFEX may decrystallize cellulose to a different extent (Chundawat et al., 2011). The



decrease in cellulose CrI upon DA pretreatment was perhaps due to simultaneous decrystallization and degradation (Xu et al., 2011).

\section{SMALL-ANGLE NEUTRON SCATTERING}

Small-angle neutron scattering (SANS) has been used before to reveal the surface roughness of biomass samples (Cetinkol et al., 2009; Cheng et al., 2011; Li et al., 2011).Due to the morphological inhomogeneity of the cell wall, the structural parameters averaged over several orders of length scales are believed to resemble its true property. The SANS data were collected in the $q$ range of $0.4-0.002 \AA^{-1}$, which reveals averaged structural properties on the order of $10-100 \mathrm{~nm}$. The scattering from corn stover samples is due to the contrast [the difference in scattering length density (SLD)] between the air and biopolymer matrix. The air may exist in the pores or cracks whose sizes vary from nanometers to microns in the cell wall (Cheng et al., 2011). As shown in Figure 2, for the untreated corn stover sample, the exponent of the fitted power law function is 3.8 , which corresponds to the scattering from a rough surface and the roughness can be characterized by a surface fractal dimension: $\mathrm{D}_{\text {surface }}=6.0-3.8=2.2$ (Cheng et al., 2011). A perfectly smooth surface has a dimension of 2.0. The dimension increases with the increase of the surface roughness. After the DA and AFEX pretreatment, as shown in Figure 2, the surface fractal dimension increased to 2.5 and 2.4 , respectively. The increase in surface roughness is caused by removal and/or redistribution of cell wall components during pretreatment processes (Chundawat et al., 2011). SEM images showed the deposition of lignin droplets on the surface of DA and AFEX pretreated samples (Selig et al., 2007; Chundawat et al., 2011). Based on the compositional analysis, there is slight decrease in lignin content after the AFEX pretreatment; while the DA pretreatment removes most of the hemicelluloses. It is believed that the in both cases the carbohydrate-lignin network was disrupted, which led to the increased cellulose accessibility (Chundawat et al., 2011). On the other hand, the surface fractal dimension drops to 2.0 for the IL 


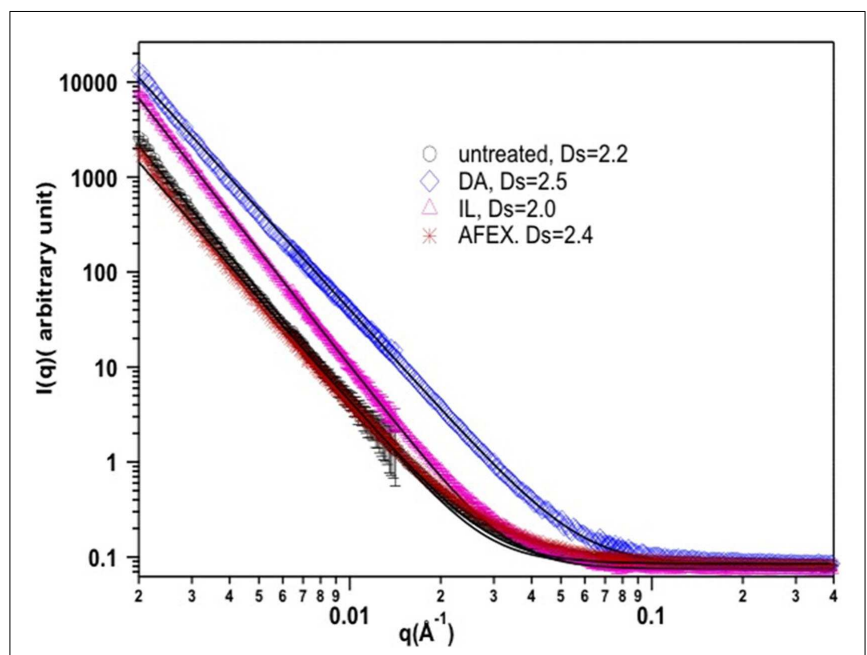

FIGURE 2 | SANS spectrum of corn stover samples before and after pretreatment. $D_{S}$ refers to surface fractal dimension.

pretreated sample. This change is correlated with the removal of most of the lignin from corn stover samples after IL pretreatment, and better defined surfaces were formed upon regeneration.

\section{CONFOCAL FLUORESCENCE AND ATOMIC FORCE MICROSCOPY}

Confocal fluorescence microscopy and AFM were used to investigate the surface morphologies of AFEX, DA, and IL pretreated corn stover at macro and micro scales. Clear differences were observed by confocal fluorescence imaging in the extent of physical alteration of the corn stover biomass upon different pretreatments (Figures 3A-C). At macro-scale investigation using fluorescence microscopy, the AFEX and DA pretreated corn stover appear similar to un-pretreated biomass (Supplementary Material). Closer observation of pretreated corn stover reveals that DA pretreated corn stover exhibiting morphological changes to cell wall, whereas AFEX pretreatment did not significantly alter the morphology of the cell walls. Compared to DA and AFEX, IL pretreatment led to significant morphological changes of the cell wall due to dissolution and then regeneration upon addition of water as an antisolvent. The IL pretreated samples do not show any resemblance to the original morphology present, and also do not fluoresce, indicative of no or very low lignin in the sample. Further investigation of AFEX pretreated corn stover using confocal fluorescence imaging showed that although there was no sign of any morphological changes in the corn stover, lignin is dissolved and displaced during AFEX (see Supplementary Material).

High-resolution surface morphologies of the pretreated corn stover were examined using high-resolution AFM imaging that can further resolve the fine surface features down to the cellulose fibers (Figures 3D-F). For the AFEX pretreated corn stover, we can clearly see that although some fraction of lignin is dissolved and re-deposited on the surface as evident by fluorescence imaging, the cellulose fibers, however, appear unaltered in size and shape. The AFM images also show lignin deposited on the surface of the cellulose fibers (confirmed with force mapping images). The detailed AFM images show very different size of the cellulose fibers before and after DA pretreatment. The cellulose fibers seem to be separated and piled together. The average width of the cellulose fibers for the DA treated samples $(209 \pm 34 \mathrm{~nm})$, which is much smaller than the AFEX treated sample $(685 \pm 119 \mathrm{~nm})$. Another interesting feature observed in these high-resolution AFM images was that these cellulose fibers appear to be composed of many cellulose nano-crystals. It appears that DA attacks the amorphous regions and breaks down the cellulose to smaller cellulose crystals (Moon et al., 2011). This effect could be generated by the combined impact of hemicellulose removal, cellulose fiber dehydration (Langan et al., 2014), and breakage of fibers at the presumed weakest point (amorphous regions in cellulose fiber). AFM images of IL pretreated corn stover show lignin-free fibers (confirmed with fluorescent imaging) that appear to be similar in width as corn stover but more randomly organized. The width of the fibers is dependent on the processing conditions (choice of anti-solvent, temperature, and stirring) during cellulose regeneration (data not shown). These results are consistent with XRD data that shows amorphous structure.

\section{EFFECT OF PRETREATMENTS ON THERMOCHEMICAL PROPERTIES OF CORN STOVER}

The thermo-gravimetric curves of biomass before and after pretreatment, as shown in Figure 4, can be divided into three regions: the hemicelluloses zone $\left(245-290^{\circ} \mathrm{C}\right)$, the cellulose zone $(290$ $350^{\circ} \mathrm{C}$ ), and the lignin zone $\left(350-500^{\circ} \mathrm{C}\right.$ ) (Singh et al., 2013; Zhang et al., 2014). We observe from the differential thermo-gravimetric (DTG) curves that for untreated corn stover, the first weight loss peak occurs at $278^{\circ} \mathrm{C}$ and the second weight loss peak occurs at $336^{\circ} \mathrm{C}$. Also, the calculated weight loss for untreated corn stover in hemicelluloses region is $28 \%$ and in cellulose region is $32 \%$. For comparison, the untreated corn stover contains $21.7 \%$ hemicelluloses and $34.9 \%$ cellulose. Interestingly, DA pretreated corn stover only shows a weight loss of $61 \%$ in the cellulose region $\left(348^{\circ} \mathrm{C}\right)$. The weight loss only in the cellulose region indicates absence of hemicellulose in the DA treated material, which is consistent with the compositional analysis (see Materials and Methods). In AFEX pretreated corn stover, we noticed an increase in decomposition temperature (from 278 to $285^{\circ} \mathrm{C}$ ) in hemicellulose region and a decrease in decomposition temperature in the cellulose zone (336$325^{\circ} \mathrm{C}$ ). Meanwhile it shows a higher weight loss of $44 \%$ in the hemicelluloses region, a lower weight loss of $15 \%$ in the cellulose region. Considering similar composition and crystallinity of untreated and AFEX pretreated corn stover, the DTG data suggest partial conversion of cellulose to lower molecular weight cellulose and the decomposition temperature of the depolymerized cellulose falls within the decomposition temperature range of the hemicellulose. In the case of IL pretreated corn stover, the first decomposition peak increases to $292^{\circ} \mathrm{C}$ and the weight loss in this region increases to $40 \%$. The second weight loss peak (decomposition temperature) of IL pretreated sample does not change when compared to untreated corn stover while weight loss in this region decreases to $27 \%$. Considering increased cellulose and hemicellulose content of IL pretreated corn stover, we hypothesize that higher weight loss in the hemicellulose region after IL pretreatment is due to conversion of crystalline cellulose into the amorphous form. 
A

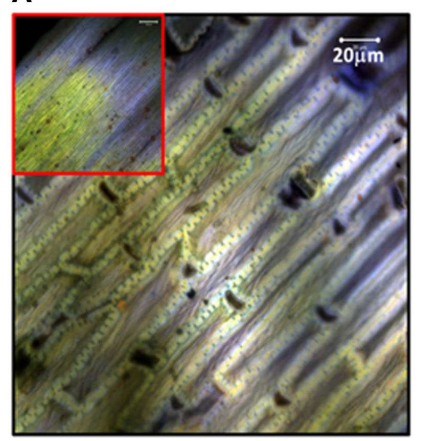

D



AFEX
B

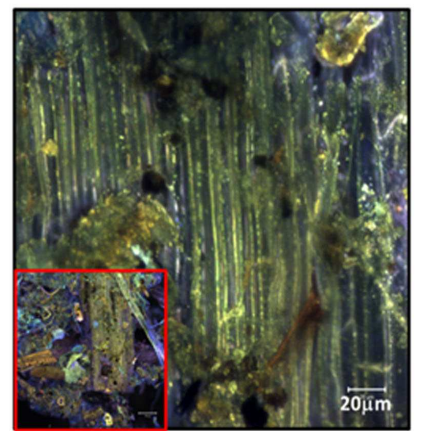

E

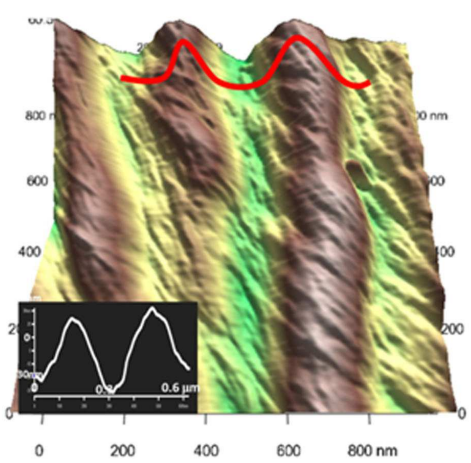

DA

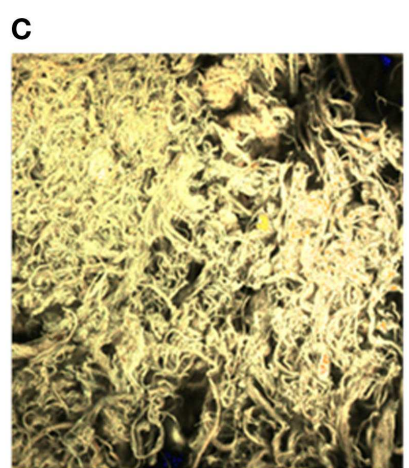

$\mathbf{F}$



IL

FIGURE 3 | Confocal fluorescence (Top) and AFM (Bottom) images of AFEX (A,D), DA (B,E), and IL pretreated (C,F) corn stover. In (A,B), the inset are low magnification images. In (D-F), the inset plots are the cross profile of the pretreated cellulose fiber.

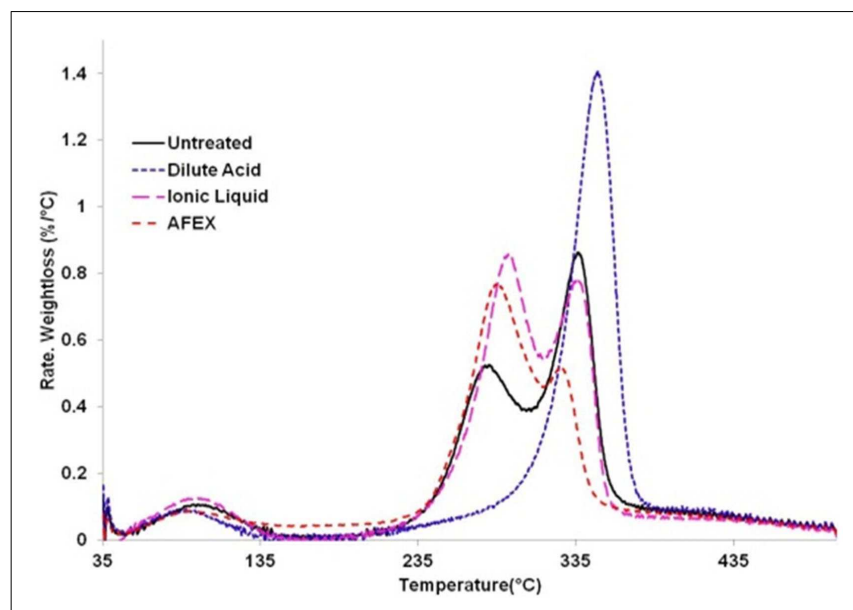

FIGURE 4 | Differential thermo-gravimetric curves of untreated and pretreated corn stover samples.

\section{CHARACTERIZATION OF CHEMICAL STRUCTURE OF CARBOHYDRATES AND LIGNIN FROM PRETREATED CORN STOVER}

2D HSQC NMR was used to elucidate structural changes of carbohydrates and lignin due to chemistry that governs different pretreatments. HSQC NMR spectra of untreated and pretreated corn stover samples from aliphatic, anomerics, and aromatic regions are shown in Figures 5-7, respectively. Assignments of the lignin ${ }^{13} \mathrm{C}-{ }^{1} \mathrm{H}$ correlation peaks in the 2D HSQC spectra of corn stover cell wall are given in Table S1 in Supplementary Material. Color-coded polymer structures correspond to colored crossed peaks in the spectra (right side, Figures 5 and 7). Aliphatic region of untreated corn stover showed lignin side chain correlations found in corn stover: $\beta$-aryl ether units (A), resinol units (C), dibenzodioxocin units (D), as well as cinnamyl alcohol end-groups (I) and methoxyls $(\mathrm{MeO})$. Prominent peaks of acetylated xylopyranosides [2-acetylated xylan (2-O-Ac- $\beta$-D-Xyl $\left.p, \mathrm{X}_{2}^{\prime}\right)$ and 3-acetylated xylan (3-O-Ac- $\left.\left.\beta-\mathrm{D}-\mathrm{Xyl} p, \mathrm{X}_{3}^{\prime}\right)\right]$ were well resolved and observed at $\delta_{\mathrm{C}} / \delta_{\mathrm{H}} 73.5 / 4.5$ and $75.0 / 4.8 \mathrm{ppm}$, respectively (Figure 6). Anomeric region correlation of untreated corn stover shows some important polysaccharide anomerics including $(1 \rightarrow 4)$-linked $\beta$-D-glucopyranosyl units ( $\beta$-D-Glcp, cellulose), $(1 \rightarrow 4)$-linked $\beta$-D-xylopyranosyl units ( $\beta$-D-Xly $p$, xylan), and $(1 \rightarrow 3)$-linked $\alpha$ $\mathrm{L}$-arabinofuranosyl units ( $\alpha$-L-Ara $p$, arabinan). Aromatic region of untreated corn stover is shown in Figure 7. Corn stover lignin is a typical syringyl/guaiacyl $(\mathrm{S} / \mathrm{G})$ lignin with low levels of $p$ hydroxyphenyl $(\mathrm{H})$ units (Figure 7 ) with $S / G$ ratio of 1.42 , which is in agreement with a value previously reported (Li et al., 2012). Ferulate (FA) and $p$-coumarates $(p \mathrm{CA})$ are observed in untreated corn stover (Figure 7). 

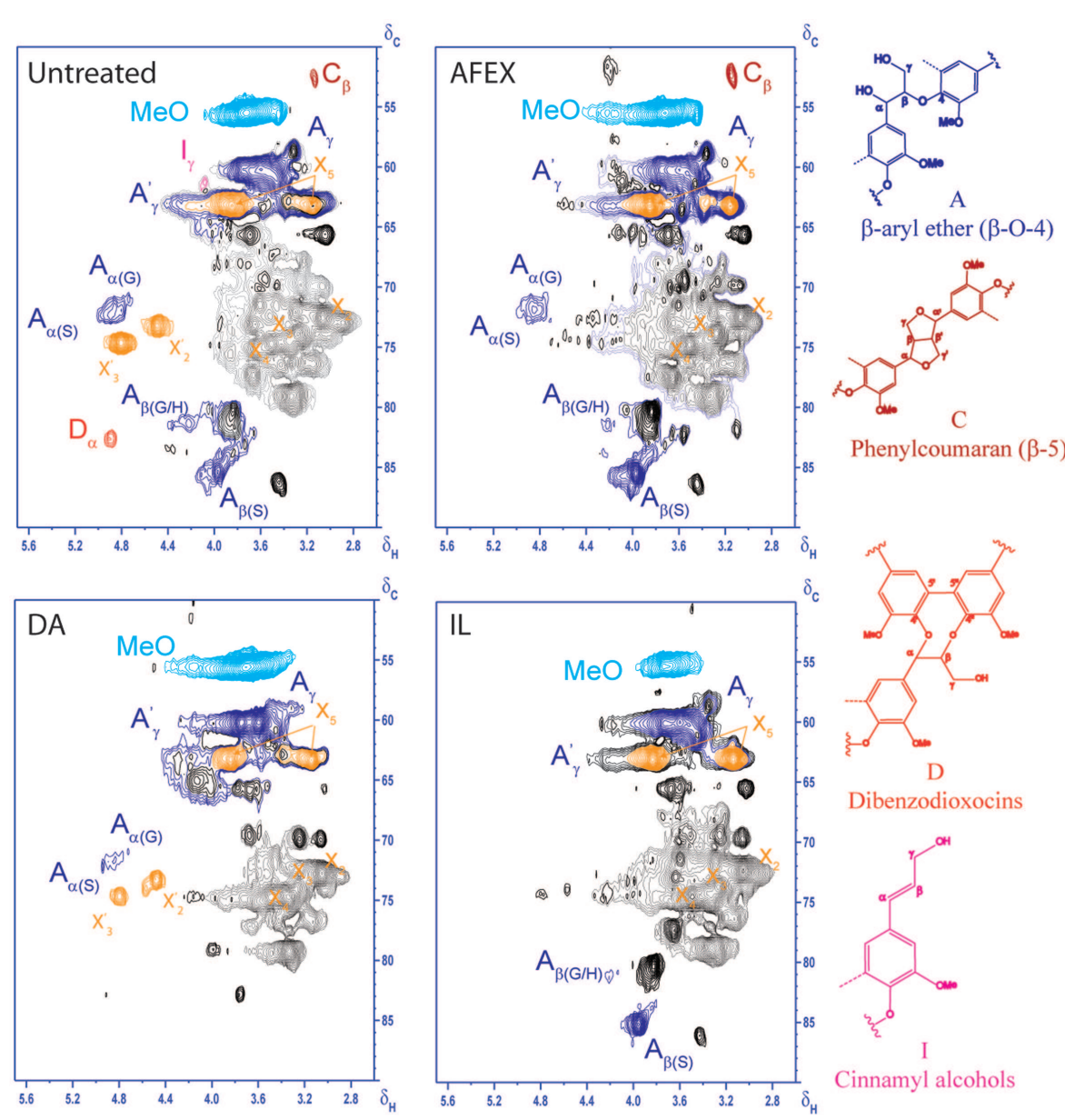

FIGURE 5 | Aliphatic region of HSOC NMR spectra of untreated and pretreated corn stover samples

\section{Ammonia fiber expansion}

Going from untreated to AFEX, $\beta$-aryl ether units appeared to be slightly lower than those of untreated corn stover (Figure 5). Cross peak integral of $\beta$-aryl ether units revealed a $\sim 17.9 \%$ reduction of $\beta$-aryl ether units compared to that of untreated corn stover. This result suggested that AFEX pretreatment did not have a strong effect on $\beta$-aryl ether linkage cleavages. Disappearance of $\mathrm{X}_{2}^{\prime}$ and $\mathrm{X}_{3}^{\prime}$ in AFEX pretreated corn stover indicated a removal of acetylated xylopyranosides, reducing steric hindrance, and increasing cellulose accessibility and enhancing carbohydrate digestibility. The depletion of dibenzodioxocin units during AFEX indicated that lignin points of branching were removed.

Polysaccharide anomerics of AFEX sample (Figure 6) showed a slightly weaker signal of $2-O-A c-\beta-D-x y l p(\mathrm{R})$. The depletion of $\beta$-correlation of FA and $p$ CA was observed. The AFEX lignin aromatic region displays depletion of $\beta$-correlation of $\mathrm{FA}$ and $p C A$. No significant reduction in $\mathrm{S}_{2,6}, \mathrm{G}_{2}$, and $p \mathrm{CA}_{2,6}$ cross peak intensities were observed from AFEX. No significant reduction in lignin side chain units and peaks in aromatic regions indicated that lignin was not depolymerized to a great extent during AFEX. However, significant reduction of dibenzodioxocin units, acetylated xylopyranosides, and FA suggests that any lignin branching points via these bonds, and lignin-carbohydrate linkages broke off during AFEX.

\section{Dilute sulfuric acid}

HSQC spectrum of DA (Figure 5) indicated $\sim 59.8 \%$ reduction in $\beta$-aryl ether units compared to that of untreated corn stover. Although cross peaks attributed to polysaccharides and some lignin side chain units are overlapped in the region $\delta_{\mathrm{C}} / \delta_{\mathrm{H}} 60-85 / 2.8-4.2 \mathrm{ppm}$, a significant decrease in intensities of xylan correlations $\left(\mathrm{X}_{2}, \mathrm{X}_{3}\right.$, and $\left.\mathrm{X}_{4}\right)$ indicated significant removal of hemicelluloses during DA. Interestingly, $\mathrm{X}_{2}^{\prime}$ and $\mathrm{X}_{3}{ }_{3}$ cross peaks were observed on DA sample, suggesting that residual hemicelluloses after DA pretreatment contained acetyl groups. Weaker signals of $2-O-A c-\beta-D-x y l p(\mathrm{R})$ and $3-O-A c-\beta-D-x y l p(R)$ in anomeric region of DA were observed, which were due to removal of hemicelluloses during DA pretreatment. Similar to AFEX, aromatic region of lignin from DA did not show a significant change in cross peak intensities. This result is in agreement with composition of DA pretreated corn stover that DA pretreatment mainly hydrolyzes labile hemicelluloses, leaving majority of lignin in the DA pretreated corn stover. $\beta$-aryl ether units of lignin 


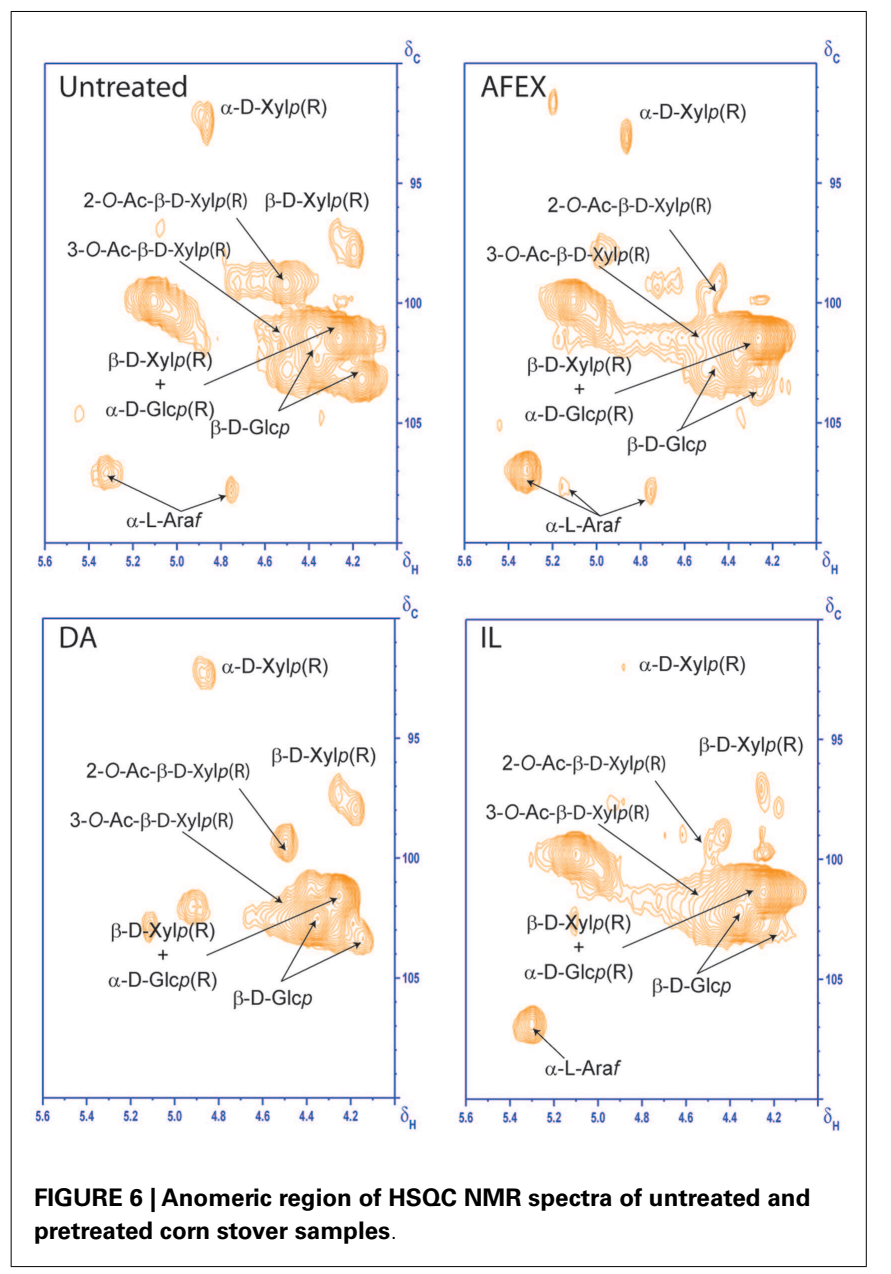

from DA were lower than that from AFEX, suggesting a greater degree of lignin de-polymerization.

\section{Ionic liquid}

Disappearance of $\beta$-aryl ether units from lignin from IL indicated the depolymerization of $\beta$-aryl ether linkages during IL pretreatment. The absence of $\mathrm{X}_{2}{ }_{2}$ and $\mathrm{X}_{3}^{\prime}$ cross peaks confirmed deacetylation of hemicelluloses during IL pretreatment. Weak intensities of $S_{2,6}, G_{5}$, and $F_{2}$ were observed in aromatic region of IL pretreated corn stover, supporting a low lignin content in IL pretreated corn stover. The depletion of $\beta$-aryl ether units and lignin aromatic units in IL pretreated corn stover suggested that lignin was depolymerized during IL pretreatment.

\section{DE-POLYMERIZATION OF LIGNIN FROM DIFFERENT PRETREATMENTS}

Enzymatic mild acidolysis lignin of corn stover was used to represent the intact lignin (lignin before pretreatment). Areanormalized elution profiles of lignin before and after pretreatments are shown in Figures 8A,B. UVA and UVF detections elucidate different aspects of the same lignin molecule. While UVA gives information of the bulk larger molecules, it is not as effective at detecting smaller molecular weight components that exhibit fluorescence, and vice versa. For a more complete insight into the polydispersity of the lignin both detection modes are used with a focus on UVA for larger molecules and UVF for smaller. In addition, the chemistry of the different pretreatments yields lignin of different structures, as indicated by the NMR data in this study. Therefore, it is possible that the lignin extraction method may affect the samples differently in terms of their chemical structure and this will affect SEC data interpretation. It is also important to note that for the DA and IL samples, if depolymerization occurs the smallest molecules maybe lost to the liquid phase, thereby increasing the average molecular weight of the samples. The compositional analysis of AFEX pretreated corn stover showed that AFEX retained most of lignin after pretreatment, while IL pretreatment showed an almost complete removal of lignin, which was confirmed by very weak signals of lignin aromatic units (Figure 7). With these caveats, the relative changes between the samples can be interpreted. Fractions were defined in the SEC chromatograms (Figure 8) to highlight changes in four key molecular weight regions (F1-4). Table 1 shows the proportion of the sample in each fraction, and also indicates the $\mathrm{Mw}$ range in these regions, as obtained by polystyrene calibration, which is thought to be more reliable for only the smallest molecules due to the difference in lignin versus polystyrene structure.

In general, AFEX shows the most similar profile to that of the EMAL lignin control. IL, followed by DA, has undergone the most significant changes in terms of profile and size, and has a greater proportion of smaller Mw components. DA shows a higher proportion of the smaller $\mathrm{Mw}$ components that are also present in the EMAL. A new category of material is present in the IL in the smallest molecular weight region in great abundance (or with chemical functionality that exhibits strong florescence), indicating even further de-polymerization. Considering the fractions in more detail, F1 depicts the largest molecules. EMAL, AFEX, and DA contain (19-26\%) of material in this range, while IL contains only $9 \%$, indicating a greater degree of de-polymerization in the IL of these largest molecules. This is also corroborated by UVF, which indicates very small quantities of material in this region. For IL, it appears that small molecular weight fragments have been cleaved from F1, to shift the sample into the F2 region (UVA). The smaller cleaved fragments are likely making a contribution to the new peak F4 (UVF). DA has the largest proportion of material in F3 by UVF analysis. This increase in abundance could either be due to depolymerization of larger fragments in the $\mathrm{F} 3$ range, or an increase in relative abundance of F3 due to removal of cleaved molecules from the largest fractions (F1 \& F2) to the liquid phase of the DA treatment.

\section{CONCLUSION}

A side-by-side comparison of the physico-chemical and thermal changes to biomass rendered by IL, DA, and AFEX pretreatment methods is necessary to better understand the origins of biomass recalcitrance and mechanism and impact of these pretreatments for further optimization. The separate hemicellulose and cellulose peaks in the TGA data allowed us to evaluate the impact of pretreatment on biomass components. The higher weight loss in the hemicelluloses region after TGA analysis for IL and AFEX pretreated corn stover indicates the ease by which thermal breakdown of these pretreated materials occurs. 



Guaiacyl

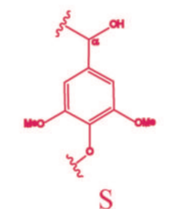

$\mathrm{S}$

Syringyl<smiles>[Y]c1ccc(C(C)C)cc1</smiles>
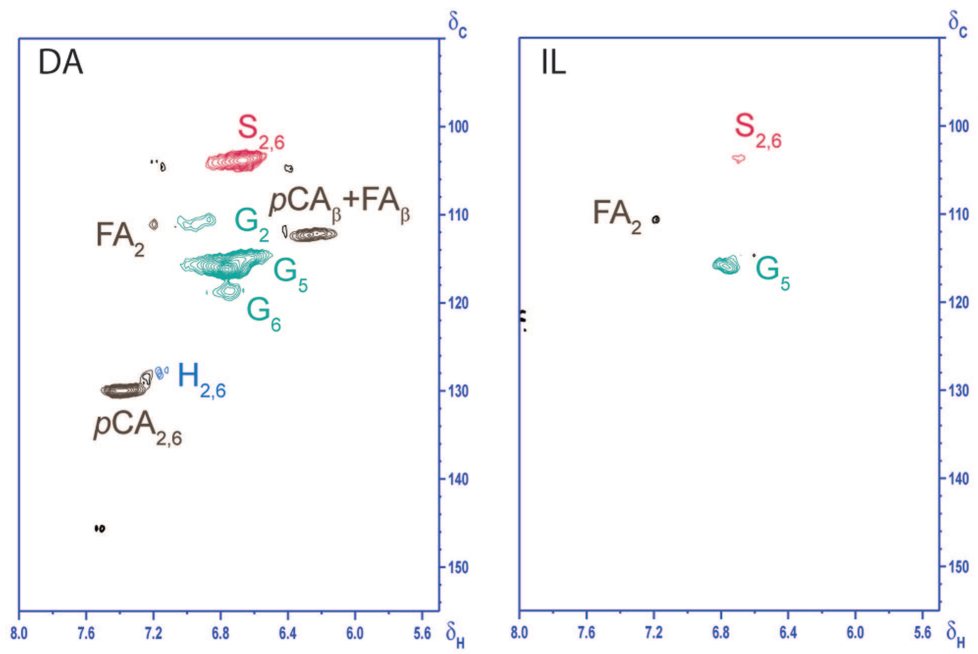

-hydroxyphenyl



Ferulate

FIGURE 7 | Aromatic region of HSOC NMR spectra of untreated and pretreated corn stover samples.
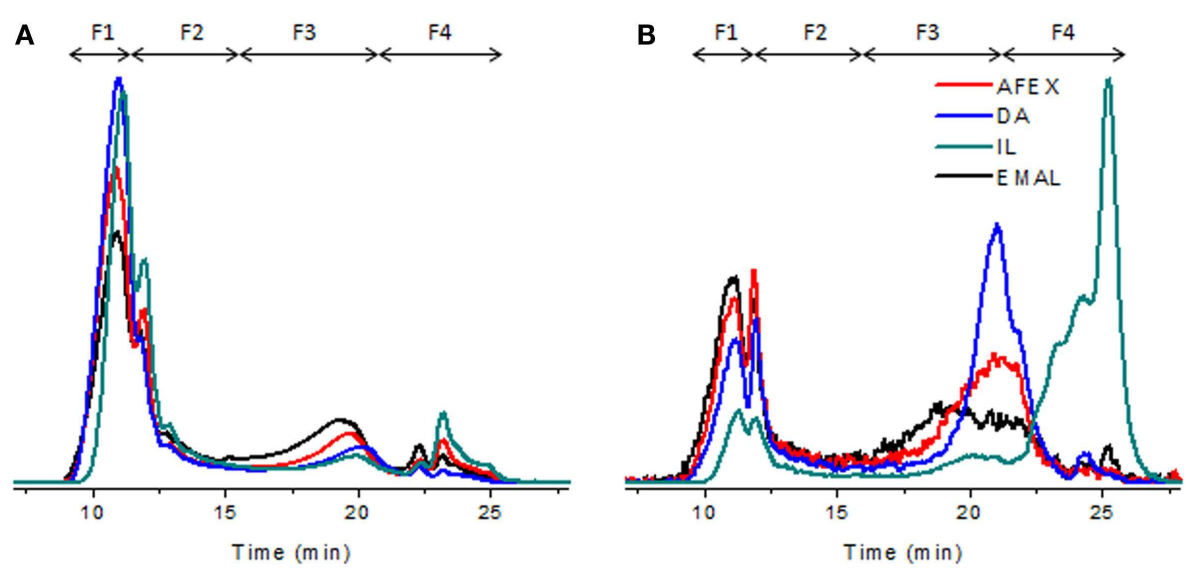

FIGURE 8 | Area-normalized SEC elution profiles of lignin before and after pretreatments. (A) UVA; (B) UVF. 
Table 1 | Elution time and relative abundance of lignin in different SEC fractions.

\begin{tabular}{llllllrr}
\hline \multicolumn{1}{c}{$\begin{array}{l}\text { Time } \\
\text { range } \\
\text { (min) }\end{array}$} & \multicolumn{2}{l}{$\begin{array}{l}\text { MW range } \\
\text { (polystyrene } \\
\text { calibration) }\end{array}$} & EMAL & AFEX & DA & IL \\
\hline \multicolumn{2}{l}{ UVA } & & & & & \\
\hline F1 & $8.0-11.7$ & $2.02 \mathrm{E}+07$ & $1.35 \mathrm{E}+06$ & 19.2 & 26.1 & 25.2 & 9.4 \\
F2 & $11.7-15.5$ & $1.35 \mathrm{E}+06$ & $8.17 \mathrm{E}+04$ & 46.0 & 50.1 & 56.1 & 65.4 \\
F3 & $15.5-21.1$ & $8.17 \mathrm{E}+04$ & 1333.15 & 26.3 & 18.8 & 14.3 & 12.1 \\
F4 & $21.1-26.0$ & 1333.15 & 36.37 & 8.4 & 4.9 & 4.5 & 12.8 \\
UVF & & & & & & \\
\hline F1 & $8.0-11.7$ & $2.02 \mathrm{E}+07$ & $1.35 \mathrm{E}+06$ & 12.7 & 3.0 & 4.8 & 0.9 \\
F2 & $11.7-15.5$ & $1.35 \mathrm{E}+06$ & $8.17 \mathrm{E}+04$ & 39.2 & 53.9 & 28.0 & 14.4 \\
F3 & $15.5-21.1$ & $8.17 \mathrm{E}+04$ & 1333.15 & 32.1 & 32.8 & 36.2 & 8.8 \\
F4 & $21.1-22.6$ & 1333.15 & 36.37 & 16.0 & 10.3 & 31.0 & 75.9 \\
\hline
\end{tabular}

Although just based on the standard compositional analysis of AFEX pretreated solid that shows minimum change to the corn stover, and it has been difficult to explain the mechanism and the causes for improved digestibility of AFEX pretreated materials in the past, our results indicate that disruption of lignincarbohydrate linkages of mainly polymeric lignin contribute to the efficiency of AFEX pretreatment. DA pretreatment appears to start with significant lignin de-polymerization, with $50 \%$ of the lignin re-condensed in the final pretreated corn stover. DA pretreated corn stover was found to be thermally more stable, however, fiber width was measured to be significantly smaller than IL and AFEX pretreated corn stover. The small fiber width and the presence of re-condensed lignin for DA may explain the slow initial hydrolysis kinetics but high sugar yields at higher enzyme loadings that were reported but difficult to understand previously. These comparative results will aid in the further development and optimization of each pretreatment technology, and provides the biofuel community a detailed knowledgebase of the impact of pretreatment as a function of type and process.

\section{ACKNOWLEDGMENTS}

We gratefully acknowledge support for this research by the Office of Biological and Environmental Research in the DOE Office of Science through the Joint BioEnergy Institute (JBEI Grant DEAC02-05CH11231), BioEnergy Science Center (BESC, Oak Ridge National Laboratory, contract number DE-PS02-06ER64304), and the Great Lakes Bioenergy Research Center (GLBRC Grant DEFC02-07ER64494). The JBEI authors would like to extend the appreciation to the BRC teams of the BioEnergy Science Center (BESC) and Michigan State of Great Lake Bioenergy Research Center (GLBRC) for providing dilute acid and AFEX pretreated corn stover samples, suggestions, and many invaluable assistance. We also appreciate the kind help of Mr. Brian Graff (MSU agronomy center) who helped in preparing the corn stover sample for this work. The research at Oak Ridge National Laboratory's High Flux Isotope Reactor was sponsored by the Scientific User Facilities Division, Office of Basic Energy Sciences, and U.S. Department of Energy.

\section{SUPPLEMENTARY MATERIAL}

The Supplementary Material for this article can be found online at http://www.frontiersin.org/Journal/10.3389/fenrg.2014.00062/ abstract

\section{REFERENCES}

Balan, V., Bals, B., Chundawat, S. P., Marshall, D., and Dale, BE. (2009). Lignocellulosic biomass pretreatment using AFEX. Methods Mol. Biol. 581, 61-77. doi:10.1007/978-1-60761-214-8_5

Balan, V., Chiaramonti, D., and Kumar, S. (2013). Review of US and EU initiatives toward development, demonstration, and commercialization of lignocellulosic biofuels. Biofuels Bioprod. Biorefin. 7, 732-759. doi:10.1002/bbb.1436

Bals, B. D., Gunawan, C., Moore, J., Teymouri, F., and Dale, B. E. (2014). Enzymatic hydrolysis of pelletized $\mathrm{AFEX}^{\mathrm{TM}}$-treated corn stover at high solid loadings. Biotechnol. Bioeng. 111, 264-271. doi:10.1002/bit.25022

Brandt, A., Grasvik, J., Hallett, J. P., and Welton, T. (2013). Deconstruction of lignocellulosic biomass with ionic liquids. Green Chem. 15, 550-583. doi:10.1039/ C2GC36364J

Cao, S., Pu, Y., Studer, M., Wyman, C., and Ragauskas, A. J. (2012). Chemical transformations of Populus trichocarpa during dilute acid pretreatment. RSC Adv. 2, 10925-10936. doi:10.1039/C2RA22045H

Cheng, G., Varanasi, P., Li, C., Liu, H., Melnichenko, Y. B., Simmons, B. A., et al. (2011). Transition of cellulose crystalline structure and surface morphology of biomass as a function of ionic liquid pretreatment and its relation to enzymatic hydrolysis. Biomacromolecules 12, 933-941. doi:10.1021/bm101240z

Chundawat, S. P. S., Donohoe, B. S., Da Costa Sousa, L., Elder, T., Agarwal, U. P., Lu, F., et al. (2011). Multi-scale visualization and characterization of lignocellulosic plant cell wall deconstruction during thermochemical pretreatment. Energy Environ. Sci. 4, 973-984. doi:10.1039/C0EE00574F

Chundawat, S. P. S., Vismeh, R., Sharma, L. N., Humpula, J. F., Da Costa Sousa, L., Chambliss, C. K., et al. (2010). Multifaceted characterization of cell wall decomposition products formed during ammonia fiber expansion (AFEX) and dilute acid based pretreatments. Bioresour. Technol. 101, 8429-8438. doi:10.1016/ j.biortech.2010.06.027

da Costa Sousa, L., Chundawat, S. P. S., Balan, V., and Dale, B. E. (2009). 'Cradleto-grave' assessment of existing lignocellulose pretreatment technologies. Curr. Opin. Biotechnol. 20, 339-347. doi:10.1016/j.copbio.2009.05.003

Cetinkol, P., Dibble, D. C., Cheng, G., Kent, M. S., Knierim, B., Auer, M., et al. (2009). Understanding the impact of ionic liquid pretreatment on eucalyptus. Biofuels 1, 33-46. doi:10.4155/bfs.09.5

Cetinkol, P., Smith-Moritz, A. M., Cheng, G., Lao, J., George, A., Hong, K., et al. (2012). Structural and chemical characterization of hardwood from tree species with applications as bioenergy feedstocks. PLOS ONE 7:e52820. doi:10.1371/ journal.pone.0052820

Foston, M., and Ragauskas, A. J. (2010). Changes in lignocellulosic supramolecular and ultrastructure during dilute acid pretreatment of Populus and switchgrass. Biomass Bioenergy 34, 1885-1895. doi:10.1016/j.biombioe.2010.07.023

Foston, M., and Ragauskas, A. J. (2012). Biomass characterization: recent progress in understanding biomass recalcitrance. Ind. Biotechnol. (New Rochelle N Y) 8, 191-208. doi:10.1089/ind.2012.0015

Gao, X., Kumar, R., Demartini, J. D., Li, H., and Wyman, C. E. (2013). Application of high throughput pretreatment and co-hydrolysis system to thermochemical pretreatment. Part 1: dilute acid. Biotechnol. Bioeng. 110, 754-762. doi:10.1002/bit.24751

Garlock, R. J., Balan, V., Dale, B. E., Ramesh Pallapolu, V., Lee, Y. Y., Kim, Y., et al. (2011). Comparative material balances around pretreatment technologies for the conversion of switchgrass to soluble sugars. Bioresour. Technol. 102, 11063-11071. doi:10.1016/j.biortech.2011.04.002

George, A., Tran, K., Morgan, T. J., Benke, P. I., Berrueco, C., Lorente, E., et al. (2011). The effect of ionic liquid cation and anion combinations on the macromolecular structure of lignins. Green Chem. 13, 3375-3385. doi:10.1039/clgc15543a

Gidh, A. V., Decker, S. R., Vinzant, T. B., Himmel, M. E., and Williford, C. (2006). Determination of lignin by size exclusion chromatography using multi angle laser light scattering. J. Chromatogr. A 1114, 102-110. doi:10.1016/j.chroma. 2006.02.044

Guerra, A., Filpponen, I., Lucia, L. A., Saquing, C., Baumberger, S., and Argyropoulos, D. S. (2006). Toward a better understanding of the lignin isolation process from wood. J. Agric. Food Chem. 54, 5939-5947. doi:10.1021/jf060722v 
Haghighi Mood, S., Hossein Golfeshan, A., Tabatabaei, M., Salehi Jouzani, G., Najafi, G. H., Gholami, M., et al. (2013). Lignocellulosic biomass to bioethanol, a comprehensive review with a focus on pretreatment. Renew. Sustain. Energ. Rev. 27, 77-93. doi:10.1016/j.rser.2013.06.033

Harun, S., Balan, V., Takriff, M. S., Hassan, O., Jahim, J., and Dale, B. (2013). Performance of AFEXTM pretreated rice straw as source of fermentable sugars: the influence of particle size. Biotechnol. Biofuels 6, 40. doi:10.1186/17546834-6-40

Heikkinen, S., Toikka, M. M., Karhunen, P. T., and Kilpeläinen, I. A. (2003). Quantitative 2D HSQC (Q-HSQC) via suppression of J-dependence of polarization transfer in NMR spectroscopy: application to wood lignin. J. Am. Chem. Soc. 125, 4362-4367. doi:10.1021/ja029035k

Kim, H., and Ralph, J. (2010). Solution-state 2D NMR of ball-milled plant cell wall gels in DMSO-d6/pyridine-d5. Org. Biomol. Chem. 8, 576-591. doi:10.1039/ b916070a

Kim, H., Ralph, J., and Akiyama, T. (2008). Solution-state 2D NMR of ball-milled plant cell wall gels in DMSO-d 6. Bioenerg. Res. 1, 56-66. doi:10.1007/s12155008-9004-Z

Kim, Y., Mosier, N. S., Ladisch, M. R., Ramesh Pallapolu, V., Lee, Y. Y., Garlock, R., et al. (2011). Comparative study on enzymatic digestibility of switchgrass varieties and harvests processed by leading pretreatment technologies. Bioresour. Technol. 102, 11089-11096. doi:10.1016/j.biortech.2011.06.054

Kumar, R., Mago, G., Balan, V., and Wyman, C. E. (2009). Physical and chemical characterizations of corn stover and poplar solids resulting from leading pretreatment technologies. Bioresour. Technol. 100, 3948-3962. doi:10.1016/j.biortech. 2009.01.075

Langan, P., Petridis, L., O’Neill, H. M., Pingali, S. V., Foston, M., Nishiyama, Y., et al. (2014). Common processes drive the thermochemical pretreatment of lignocellulosic biomass. Green Chem. 16, 63-68. doi:10.1039/C3GC41962B

Lau, M., Gunawan, C., and Dale, B. (2009). The impacts of pretreatment on the fermentability of pretreated lignocellulosic biomass: a comparative evaluation between ammonia fiber expansion and dilute acid pretreatment. Biotechnol. Biofuels 2, 30. doi:10.1186/1754-6834-2-30

Lau, M. W., and Dale, B. E. (2009). Cellulosic ethanol production from AFEX-treated corn stover using Saccharomyces cerevisiae 424A(LNH-ST). Proc. Natl. Acad. Sci. U.S.A. 106, 1368-1373. doi:10.1073/pnas.0812364106

Li, C., Cheng, G., Balan, V., Kent, M. S., Ong, M., Chundawat, S. P. S., et al. (2011). Influence of physico-chemical changes on enzymatic digestibility of ionic liquid and AFEX pretreated corn stover. Bioresour. Technol. 102, 6928-6936. doi:10.1016/j.biortech.2011.04.005

Li, C., Knierim, B., Manisseri, C., Arora, R., Scheller, H. V., Auer, M., et al. (2010). ). Comparison of dilute acid and ionic liquid pretreatment of switchgrass: biomass recalcitrance, delignification and enzymatic saccharification. Bioresour. Technol. 101, 4900-4906. doi:10.1016/j.biortech.2009.10.066

Li, C., Sun, L., Simmons, B., and Singh, S. (2013). Comparing the recalcitrance of eucalyptus, pine, and switchgrass using ionic liquid and dilute acid pretreatments. Bioenerg. Res. 6, 14-23. doi:10.1007/s12155-012-9220-4

Li, M., Foster, C., Kelkar, S., Pu, Y., Holmes, D., Ragauskas, A., et al. (2012). Structural characterization of alkaline hydrogen peroxide pretreated grasses exhibiting diverse lignin phenotypes. Biotechnol. Biofuels 5, 38. doi:10.1186/ 1754-6834-5-38

Moon, R. J., Martini, A., Nairn, J., Simonsen, J., and Youngblood, J. (2011). Cellulose nanomaterials review: structure, properties and nanocomposites. Chem. Soc. Rev. 40, 3941-3994. doi:10.1039/C0CS00108B

Mora-Pale, M., Meli, L., Doherty, T. V., Linhardt, R. J., and Dordick, J. S. (2011). Room temperature ionic liquids as emerging solvents for the pretreatment of lignocellulosic biomass. Biotechnol. Bioeng. 108, 1229-1245. doi:10.1002/bit. 23108

Muhammad, N., Omar, W. N., Man, Z., Bustam, M. A., Rafiq, S., and Uemura, Y. (2012). Effect of ionic liquid treatment on pyrolysis products from bamboo. Ind. Eng. Chem. Res. 51, 2280-2289. doi:10.1021/ie2014313

Ong, R., Chundawat, S. S., Hodge, D., Keskar, S., and Dale, B. (2014). "Linking plant biology and pretreatment: understanding the structure and organization of the plant cell wall and interactions with cellulosic biofuel production," in Plants and Bioenergy, eds M. C. McCann, M. S. Buckeridge, and N. C. Carpita (New York, NY: Springer), 231-253.

Pallapolu, V. R., Lee, Y. Y., Garlock, R. J., Balan, V., Dale, B. E., Kim, Y., et al. (2011). Effects of enzyme loading and $\beta$-glucosidase supplementation on enzymatic hydrolysis of switchgrass processed by leading pretreatment technologies. Bioresour. Technol. 102, 11115-11120. doi:10.1016/j.biortech.2011.03.085

Poletto, M., Zattera, A. J., and Santana, R. M. C. (2012). Thermal decomposition of wood: kinetics and degradation mechanisms. Bioresour. Technol. 126, 7-12. doi:10.1016/j.biortech.2012.08.133

Pu, Y., Hu, F., Huang, F., Davison, B. H., and Ragauskas, A. J. (2013). Assessing the molecular structure basis for biomass recalcitrance during dilute acid and hydrothermal pretreatments. Biotechnol. Biofuels 6, 15. doi:10.1186/1754-68346-15

Saha, B. C., Iten, L. B., Cotta, M. A., and Wu, Y. V. (2005). Dilute acid pretreatment, enzymatic saccharification, and fermentation of rice hulls to ethanol. Biotechnol. Prog. 21, 816-822. doi:10.1021/bp049564n

Samuel, R., Foston, M., Jaing, N., Cao, S., Allison, L., Studer, M., et al. (2011a). HSQC (heteronuclear single quantum coherence) 13C-1H correlation spectra of whole biomass in perdeuterated pyridinium chloride-DMSO system: an effective tool for evaluating pretreatment. Fuel 90, 2836-2842. doi:10.1016/j.fuel. 2011.04.021

Samuel, R., Foston, M., Jiang, N., Allison, L., and Ragauskas, A. J. (2011b). Structural changes in switchgrass lignin and hemicelluloses during pretreatments by NMR analysis. Polym. Degrad. Stab. 96, 2002-2009. doi:10.1016/j.polymdegradstab. 2011.08.015

Sathitsuksanoh, N., Holtman, K. M., Yelle, D. J., Morgan, T., Stavila, V., Pelton, J., et al. (2014). Lignin fate and characterization during ionic liquid biomass pretreatment for renewable chemicals and fuels production. Green Chem. 16, 1236-1247. doi:10.1039/C3GC42295J

Selig, M. J., Viamajala, S., Decker, S. R., Tucker, M. P., Himmel, M. E., and Vinzant, T. B. (2007). Deposition of lignin droplets produced during dilute acid pretreatment of maize stems retards enzymatic hydrolysis of cellulose. Biotechnol. Prog. 23, 1333-1339. doi:10.1021/bp0702018

Singh, R., Shukla, A., Tiwari, S., and Srivastava, M. (2014). A review on delignification of lignocellulosic biomass for enhancement of ethanol production potential. Renew. Sustain. Energ. Rev. 32, 713-728. doi:10.1016/j.rser.2014.01.051

Singh, S., Simmons, B. A., and Vogel, K. P. (2009). Visualization of biomass solubilization and cellulose regeneration during ionic liquid pretreatment of switchgrass. Biotechnol. Bioeng. 104, 68-75. doi:10.1002/bit.22386

Singh, S., Varanasi, P., Singh, P., Adams, P. D., Auer, M., and Simmons, B. A. (2013). Understanding the impact of ionic liquid pretreatment on cellulose and lignin via thermochemical analysis. Biomass Bioenergy 54, 276-283. doi:10.1016/j.biombioe.2013.02.035

Sun, Y., and Cheng, J. J. (2005). Dilute acid pretreatment of rye straw and bermudagrass for ethanol production. Bioresour. Technol. 96, 1599-1606. doi:10.1016/j. biortech.2004.12.022

Tadesse, H., and Luque, R. (2011). Advances on biomass pretreatment using ionic liquids: an overview. Energy Environ. Sci. 4, 3913-3929. doi:10.1039/ C0EE00667J

Tao, L., Aden, A., Elander, R. T., Pallapolu, V. R., Lee, Y. Y., Garlock, R. J., et al. (2011). Process and technoeconomic analysis of leading pretreatment technologies for lignocellulosic ethanol production using switchgrass. Bioresour. Technol. 102, 11105-11114. doi:10.1016/j.biortech.2011.07.051

Verdia, P., Brandt, A., Hallett, J. P., Ray, M. J., and Welton, T. (2014). Fractionation of lignocellulosic biomass with the ionic liquid 1-butylimidazolium hydrogen sulfate. Green Chem. 16, 1617-1627. doi:10.1039/C3GC41742E

Wyman, C. E., Balan, V., Dale, B. E., Elander, R. T., Falls, M., Hames, B., et al. (2011). Comparative data on effects of leading pretreatments and enzyme loadings and formulations on sugar yields from different switchgrass sources. Bioresour. Technol. 102, 11052-11062. doi:10.1016/j.biortech.2011.06.069

Xu, F., Shi, Y.-C., Wu, X., Theerarattananoon, K., Staggenborg, S., and Wang, D. (2011). Sulfuric acid pretreatment and enzymatic hydrolysis of photoperiod sensitive sorghum for ethanol production. Bioprocess Biosyst. Eng. 34, 485-492. doi:10.1007/s00449-010-0492-9

Yang, B., Dai, Z., Ding, S.-Y., and Wyman, C. E. (2011). Enzymatic hydrolysis of cellulosic biomass. Biofuels 2, 421-450. doi:10.4155/bfs.11.116

Yang, B., and Wyman, C. E. (2008). Pretreatment: the key to unlocking low-cost cellulosic ethanol. Biofuels Bioprod. Biorefin. 2, 26-40. doi:10.1002/bbb.49

Yelle, D., Kaparaju, P., Hunt, C., Hirth, K., Kim, H., Ralph, J., et al. (2013). Twodimensional NMR evidence for cleavage of lignin and xylan substituents in wheat straw through hydrothermal pretreatment and enzymatic hydrolysis. Bioenerg. Res. 6, 211-221. doi:10.1007/s12155-012-9247-6 
Yelle, D. J., Ralph, J., and Frihart, C. R. (2008). Characterization of nonderivatized plant cell walls using high-resolution solution-state NMR spectroscopy. Magn. Reson. Chem. 46, 508-517. doi:10.1002/mrc.2201

Zhang, J., Feng, L., Wang, D., Zhang, R., Liu, G., and Cheng, G. (2014). Thermogravimetric analysis of lignocellulosic biomass with ionic liquid pretreatment. Bioresour. Technol. 153, 379-382. doi:10.1016/j.biortech.2013.12.004

Zhao, X., Zhang, L., and Liu, D. (2012). Biomass recalcitrance. Part I: the chemical compositions and physical structures affecting the enzymatic hydrolysis of lignocellulose. Biofuels Bioprod. Biorefin. 6, 465-482. doi:10.1002/ bbb. 1331

Conflict of Interest Statement: The authors declare that the research was conducted in the absence of any commercial or financial relationships that could be construed as a potential conflict of interest.
Received: 14 September 2014; paper pending published: 11 October 2014; accepted: 18 December 2014; published online: 06 February 2015.

Citation: Singh S, Cheng G, Sathitsuksanoh N, Wu D, Varanasi P, George A, Balan V, Gao X, Kumar R, Dale BE, Wyman CE and Simmons BA (2015) Comparison of different biomass pretreatment techniques and their impact on chemistry and structure. Front. Energy Res. 2:62. doi: 10.3389/fenrg.2014.00062

This article was submitted to Bioenergy and Biofuels, a section of the journal Frontiers in Energy Research.

Copyright (c) 2015 Singh, Cheng, Sathitsuksanoh, Wu, Varanasi, George, Balan, Gao, Kumar, Dale, Wyman and Simmons. This is an open-access article distributed under the terms of the Creative Commons Attribution License (CC BY). The use, distribution or reproduction in other forums is permitted, provided the original author (s) or licensor are credited and that the original publication in this journal is cited, in accordance with accepted academic practice. No use, distribution or reproduction is permitted which does not comply with these terms. 